\title{
Usefulness of ST segment elevations as predictors of electrocardiographic signs of necrosis in patients with acute myocardial infarction ${ }^{1}$
}

\author{
JOSEPH ASKENAZI, PETER R. MAROKO, MICHAEL LESCH, AND \\ EUGENE BRAUNWALD
}

From the Departments of Medicine, Harvard Medical School and Peter Bent Brigham Hospital, Boston, Massachusetts, U.S.A.

The purpose of this study was to determine whether the early analysis of the electrocardiogram in patients with acute myocardial infarction may be useful in predicting the development of myocardial necrosis. It is based on observations in the dog that epicardial ST segment elevations ( $S T \uparrow$ ) consequent to experimental coronary artery occlusion predict the development of myocardial necrosis, as judged by histological appearance, electron microscopy, myocardial creatine kinase activity, as well as the development of new $Q$ waves and the decline of $R$ waves in epicardial leads. Accordingly, the usefulness of early $S T \uparrow$ in the standard 12-lead electrocardiogram as a predictor of the subsequent development of electrocardiographic signs of necrosis was assessed. Studies were made on 51 patients with acute myocardial infarction who were admitted to the hospital within 8 hours of the onset of chest pain. Each $Q R S$ complex was scored from 0 to 4 as follows: $0=$ normal $Q R S ; 1=$ fall in $R$ wave amplitude by at least $0.2 \mathrm{mV}$ and 50 per cent of control; $2=Q \geq 0.2 \mathrm{mV}$ in depth and $\geq 0.04 \mathrm{~s}$ in duration, but $Q<R ; 3=$ same as score 2 but $Q>R$; and $4=Q S$. Leads considered to be vulnerable for the development of necrosis were those with a score of 0 or 2 with $S T \uparrow \geq 0.15 \mathrm{mV}$ on admission. Changes in score $\geq 2$ occurred within 5 days in an average of $70.4 \pm 4.5$ per cent (SEM) of the vulnerable leads in the 68 vulnerable leads in the 27 patients with diaphragmatic myocardial infarction and in an average of $56 \cdot 7 \pm 7 \cdot 5$ per cent of the 76 vulnerable leads in 24 patients with anterior myocardial infarction (leads V1 to V6). The sum of the height of $R$ waves $(\Sigma R)$ in the vulnerable leads fell by $63 \cdot 7 \pm 3 \cdot 8$ per cent in patients with diaphragmatic myocardial infarction and $76.1 \pm 4.9$ per cent in patients with anterior myocardial infarction. Approximately four-fifths of the fall in $\Sigma R$ and of score changes $\geq 2$ which had occurred by the fifth day had already developed one day after admission.

It is concluded that there is a predictable percentage of leads with $S T \uparrow$ elevations in the initial electrocardiographic recordings, which ultimately develop signs of necrosis. A significant reduction in this percentage after a therapeutic intervention may be indicative of the sparing of jeopardised myocardium, and thus may provide a much needed approach to assessing the effects of interventions on the extent of myocardial necrosis.

The concept that the size of a myocardial infarct can be modified in experimental animals after coronary occlusion has gained support from studies using the method of epicardial ST segment mapping, correlated with analyses of creatine kinase (CK) activity and histological appearance of myocardial biopsies (Maroko et al., 1971, 1972b; Maroko and Braunwald, 1973; Braunwald and Maroko, 1974; Hirshfeld et al., 1974; Epstein et al.,

${ }^{1}$ This study was supported in part by a Contract under the Cardiac Diseases Branch, Division of Heart and Vascular Diseases, National Heart and Lung Institute, NIH, Department of HEW, Bethesda, Maryland, U.S.A.

Received for publication 6 December 1976
1975). In addition, the fact that the size of experimentally produced infarcts can be limited has been shown by a method totally independent of epicardial ST segment mapping. Histological analysis of the posterior papillary muscle after occlusion of the circumflex coronary artery has shown a reduction in necrosis in animals receiving propranolol (Reimer et al., 1973) or mannitol (Reimer et al., 1975). Thus, limitation of infarct size in animals has now been documented by two totally unrelated techniques. The potential clinical importance of these findings has been heightened by laboratory evidence that the quantity of myocardium which can 
be salvaged by these interventions is substantial and that it is possible to start treatment a number of hours after occlusion which will still be effective (Maroko et al., 1972a; Maroko and Braunwald, 1973).

The salvage of contractile tissue otherwise destined to undergo necrosis may be expected to reduce the incidence of heart failure and ultimately of the mortality secondary to myocardial infarction (Harnarayan et al., 1970; Scheidt et al., 1970; Page et al., 1971; Dizadji et al., 1972). One of the most formidable barriers to the clinical application of this concept is the lack of a suitable technique to assess the efficacy, or lack thereof, of these interventions designed to accomplish this salvage. Specifically, a technique is needed which can be applied to patients at an early stage in the course of an infarction, when the injury to considerable quantities of myocardium is still in the reversible phase, which will predict the ultimate amount of myocardial necrosis to be anticipated, and which can then be repeated at a later time to assess the amount of damage which has actually occurred.

One technique that has been employed is the analysis of the rate of fall of ST segment elevation in the epicardial or praecordial electrocardiograms (Maroko et al., 1971; Redwood et al., 1972; Maroko and Braunwald, 1973; Braunwald and Maroko, 1974; Reid et al., 1974; Borer et al., 1975; Come et al., 1975; Epstein et al., 1975; Flaherty et al., 1975; Maroko et al., 1975); this method has the advantage of showing practically instantaneous changes in reversible tissue damage, thus making it possible to monitor increases or reductions of myocardial ischaemic injury (Maroko et al., 1972a). This property, together with the simplicity and rapidity of the method, makes it suitable for the rapid evaluation of the effect of treatment of ischaemic injury. ST segment mapping, however, does not provide an absolute measurement of the size of the ischaemic zone. In addition, it is critical to recognise that factors other than ischaemia can affect the height of the ST segment. These include, but are not limited to, alterations in $p \mathrm{H}$ and ion concentrations, temperature changes, drugs such as quinidine and digitalis, the development of localised intraventricular conduction defects, and epicardial injury caused by pericarditis and myocardial injury not of ischaemic origin. Consequently, it would be misleading automatically to attribute changes in ST segments exclusively to alterations caused by ischaemia.

It has become clear from animal experiments (Radvany et al., 1975; Hillis et al., 1976) that epicardial sites which show ST segment elevation shortly after coronary occlusion have a predictable progression to $\mathrm{QRS}$ configurations indicative of necrosis ( $R$ wave fall and $Q$ wave development). Interventions which have been shown to protect ischaemic myocardium by diminishing both $\mathrm{CK}$ depletion and the development of histological evidence of necrosis, reduce this fall of $R$ wave and $Q$ wave development.

The present investigation was undertaken to determine whether these concepts could be extended to the clinical sphere and specifically to ascertain whether in patients with acute myocardial infarction early ST segment elevations recorded in the 12 standard leads can be used to predict the subsequent development of electrocardiographic signs of necrosis, as reflected in the appearance of pathological $Q$ waves and fall in $R$ wave voltages in the same leads.

\section{Methods}

The electrocardiograms of 51 consecutive patients with acute myocardial infarctions admitted to the Peter Bent Brigham Hospital whose electrocardiograms satisfied the following criteria were analysed: (1) Acute myocardial infarction diagnosed by a typical history, typical electrocardiographic pattern of an acute transmural myocardial infarction by ST-T wave changes, and increases in serum $\mathrm{CK}, \mathrm{LDH}$, and SGOT activities to at least 3 times the upper limits of normal.

(2) Availability of an electrocardiogram recorded within 8 hours of the onset of pain $\left(E_{C G}\right)$ in which at least one of the leads (other than aVR) showed both an ST segment elevation $\geq 0.15$ $\mathrm{mV}$ and a score of 0 or 2 in the same lead (for definition of score see below). Thus, the electrocardiographic criteria require the existence of ST segment elevations independent of existence of $Q$ waves and the existence in the same leads of $\mathrm{QRS}$ complexes that could undergo further necrosis.

(3) Availability of electrocardiograms recorded 1 day $\left(E C G_{1 d}\right)$ and 5 days $\left(E G_{5 d}\right)$ after admission.

Patients with intraventricular conduction defects, bundle-branch block, hemiblock, and third degree atrioventricular block were excluded.

The patients consisted of 43 men and 8 women who averaged $60 \cdot 2 \pm 11.8$ years (SD) in age. The time from the onset of pain to the first electrocardiogram averaged $4 \cdot 7 \pm 2 \cdot 1$ hours (SD).

In order to examine the evolution of the QRS complex throughout the first days after acute myocardial infarction the 3 electrocardiograms (i.e. $\mathrm{ECG}_{0}, \mathrm{ECG}_{1 \mathrm{~d}}$, and $\mathrm{ECG}_{5 \mathrm{~d}}$ ) were analysed as follows: 


\section{(1) QRS 'SCORES'}

The QRS complexes were scored from 0 to 4 regardless of abnormalities of the ST segment or the T waves (Fig. 1) as follows: (i) A score of 0 represented a QRS with normal appearance, i.e. $Q$ wave $<0.2 \mathrm{mV}$ and/or $<40 \mathrm{~ms}$; (ii) a score of 1 represented a decline in $R$ wave amplitude by $\geq 0.2 \mathrm{mV}$ and $\geq 50$ per cent from that recorded in $E^{2} G_{0}$; the $Q$ wave remained $<0.2 \mathrm{mV}$ and $<40 \mathrm{~ms}$; (iii) a score of 2 represented a complex with $Q$ wave amplitude of $\geq 0.2 \mathrm{mV}$, duration of $\geq 40 \mathrm{~ms}$ and a $Q / R \leq 1 \cdot 0$; (iv) a score of 3 represented a complex identical to that defined for a score of 2, except that $Q / R>1.0$; (v) a score of 4 represented a $Q S$ complex.

In the initial tracing $\left(\mathrm{ECG}_{0}\right.$ ) leads having $\mathrm{ST}$ segment elevations $\geq 0.15 \mathrm{mV}$ and score of 0 or 2 were considered to be vulnerable for the development of necrosis. The percentage of such leads in which the scores increased by more than 1 or 2 in $\mathrm{ECG}_{1 \mathrm{~d}}$ and $\mathrm{ECG}_{5 \mathrm{~d}}$ were determined.

\section{(2) ANALYSIS OF FALL IN HEIGHT}

\section{OF $R$ WAVES}

$\mathbf{R}$ wave heights were measured in all vulnerable sites, as defined above, and the change in the sum of $R$ waves $(\Sigma R)$ in all vulnerable sites, in $E C_{1} d$ and $\mathrm{ECG}_{5} \mathrm{~d}$, in each patient was determined and expressed both in $\mathrm{mV}$ and as a percentage of the $\Sigma R$ in $\mathbf{E C G}_{0}$.

In patients with a diaphragmatic wall myocardial infarction (group 1, 27 patients), these analyses were carried out both in lead aVF alone and in leads II, III, and aVF considered together. In patients with acute anterior myocardial infarction only leads V1 through V6 (group 2, 24 patients) were analysed. Comparisons of $\mathrm{ECG}_{0}$ and $\mathrm{ECG}_{1 \mathrm{a}}$ and of $\mathrm{ECG}_{0}$ and $\mathrm{ECG}_{5 \mathrm{~d}}$ were made using Student's $t$ test for paired observations (Snedecor and Cochran, 1967).

\section{Results}

\section{GROUP 1}

The 27 patients with diaphragmatic wall myocardial infarction in whom the standard unipolar and bipolar leads (II, III, and aVF) were analysed (Fig. 2) had 68 vulnerable leads. The percentage of vulnerable leads per patient which showed a change in score $\geq 1$ averaged $60.5 \pm 7.9$ per cent (SEM) at day 1 and $74 \cdot 1 \pm 6 \cdot 7$ per cent at day 5 (Fig. 3) while for a change in score $\geq 2$ these values averaged $56 \cdot 7 \pm 6.0$ per cent at day 1 and $70.4 \pm 4.5$ per cent at day 5 (Fig. 4). The $\Sigma R$ in vulnerable sites averaged $1.83 \pm 0.22 \mathrm{mV}$ per patient in $\mathrm{ECG}_{0}$ and had declined by an average of $0.93 \pm 0.15 \mathrm{mV}$ (i.e. $50 \cdot 8 \pm 4 \cdot 2 \%$ ) at day 1 and by $1 \cdot 15 \pm 0.81 \mathrm{mV}$ (i.e.
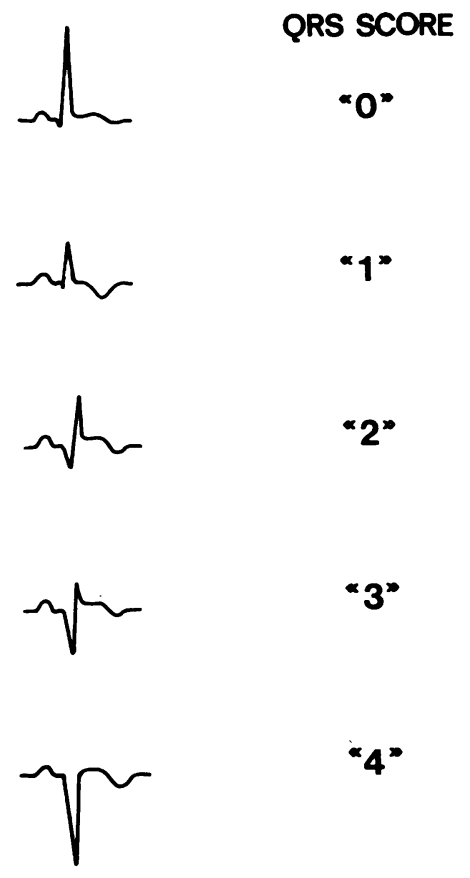

Fig. 1 Method of $Q R S$ scoring, as described in the text.

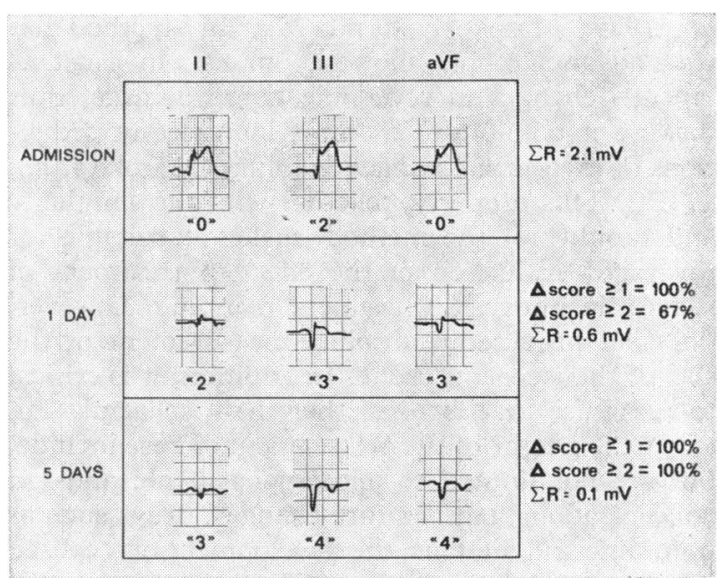

Fig. 2 Electrocardiogram from a patient with an acute diaphragmatic myocardial infarct. Leads II, III, and aVF on admission are considered to be vulnerable sites, as defined in the text, since in each, $S T$ segment elevation $\geqq 0.15 \mathrm{mV}$ and the score does not exceed 2 .

Twenty-four hours later all 3 leads (100\%) evolved a change of score $\geqq 1$, and 2 of the 3 leads (67\%), i.e. II and $a V F$ developed a change in score $\geq 2$. By 5 days all 3 leads changed score $\geqq 2$. $\Sigma R$ fell by $1.5 \mathrm{mV}(71 \%)$ in 1 day and by $2.0 \mathrm{mV}(95 \%)$ in 5 days. 
$63 \cdot 7 \pm 3 \cdot 8 \%$ ) at day 5 (Fig. 5).

In the 27 patients with diaphragmatic wall myocardial infarction, lead aVF alone was also analysed. In 20 of these 27 vulnerable leads (74.1\%) exhibited a change of score $\geq 1$ at day 1 and 96.3 per cent at day 5 . The comparable values for changes in score $\geq 2$ were 63.0 per cent at day 1 and 77.8 per cent at day 5. The $R$ wave voltage in these 27 vulnerable leads averaged $0.61 \pm 0.09 \mathrm{mV}$ and it declined by an average of $0.32 \pm 0.06$ (i.e. $56.1 \pm$ $6.5 \%$ ) at day 1 and by $0.41 \pm 0.07 \mathrm{mV}$ (i.e. $70 \cdot 1 \pm$ $5 \cdot 5 \%$ ) at day 5 .

\section{GROUP 2}

The 24 patients with anterior myocardial infarction in whom the standard praecordial leads (V1-V6) were analysed had 76 vulnerable sites (Fig. 6). The percentage of vulnerable leads per patient which showed a change in score $\geq 1$ averaged $61 \cdot 7 \pm 8 \cdot 2$ per cent at day 1 and $80.8 \pm 4.5$ per cent at day 5 (Fig. 3 and Table), while for a change in score $\geq 2$ these values averaged $31.5 \pm 7.4$ per cent at day 1 and $56 \cdot 7 \pm 7.5$ per cent at day 5 (Fig. 4 and Table). The $\Sigma \mathbf{R}$ in the vulnerable leads averaged $2.01 \pm$ $0.48 \mathrm{mV}$ per patient in $\mathrm{ECG}_{0}$ and declined by an average of $1.22 \pm 0.38 \mathrm{mV}$ (i.e. $55 \cdot 8 \pm 6.2 \%$ ) at day 1 and by $1.40 \pm 0.40 \mathrm{mV}$ (i.e. $76 \cdot 1 \pm 4.9 \%$ ) at day 5 (Fig. 5 and Table).

\section{Discussion}

Both experimental and clinical pathological studies

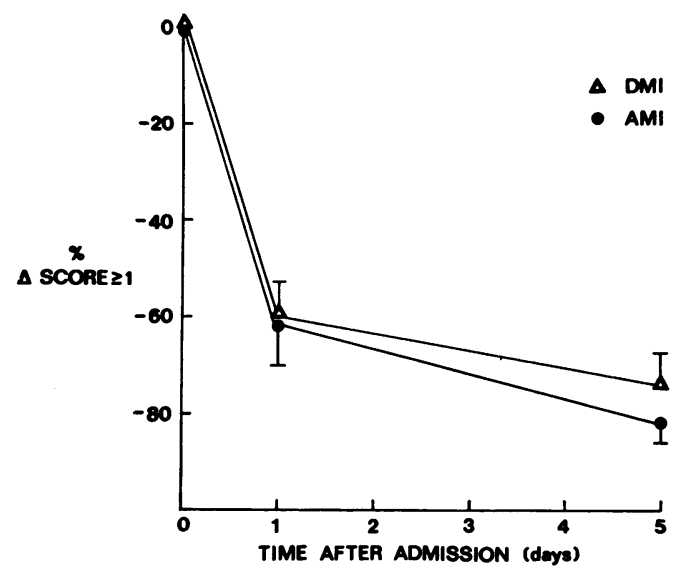

Fig. 3 Average ( \pm SEM) per cent of vulnerable sites per patient which changed in score $\geqq 1$ in 1 and 5 days after admission in 27 patients with diaphragmatic wall infarcts (DMI, triangles) and in 24 patients with anterior myocardial infarction (AMI, circles). Of the changes occurring on the fifth day approximately four-fifths had already occurred by the first day. carried out during the past 40 years have shown a correlation between changes in the QRS complex and the extent of myocardial necrosis in patients and experimental animals with coronary occlusion. Wilson et al. (1933) noted the development of QS complexes in epicardial leads as indicators of transmural myocardial necrosis. Prinzmetal et al.

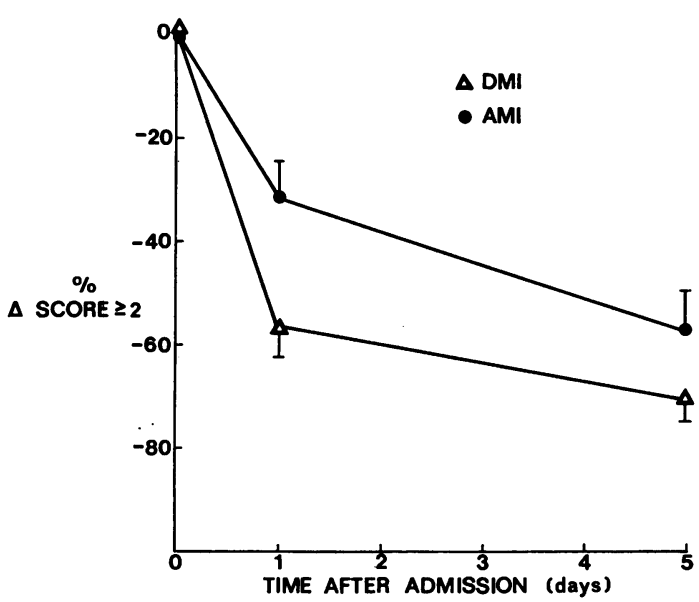

Fig. 4 Average ( $\pm S E M$ ) per cent of vulnerable sites per patient which changed in score $\geqq 2$ in 1 and 5 days after admission in 27 patients with diaphragmatic wall myocardial infarction (DMI, triangles) and in 24 patients with anterior myocardial infarction ( $A M I$, circles).

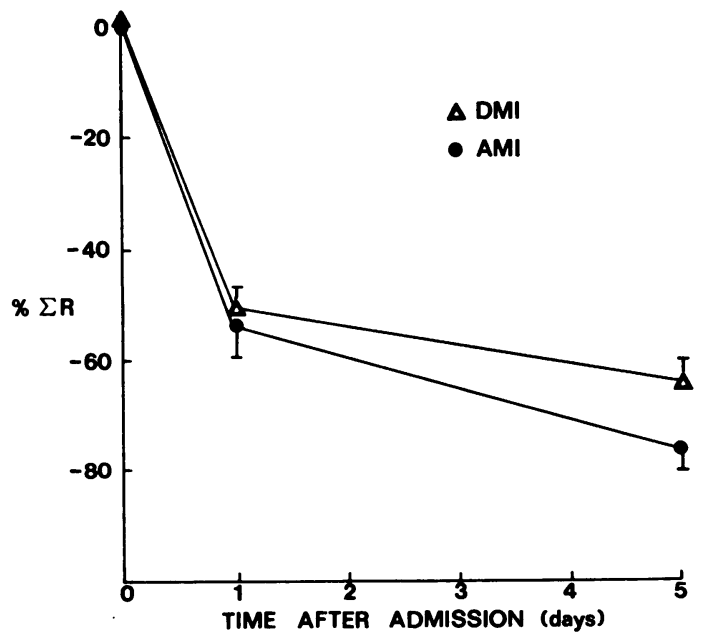

Fig. 5 Per cent fall in the sum of $R$ waves ( $\Sigma R$ ) in vulnerable sites in patients with acute diaphragmatic wall myocardial infarction (DMI, triangles) and in the 24 patients with acute anterior myocardial infarction ( $A M I$, circles). 


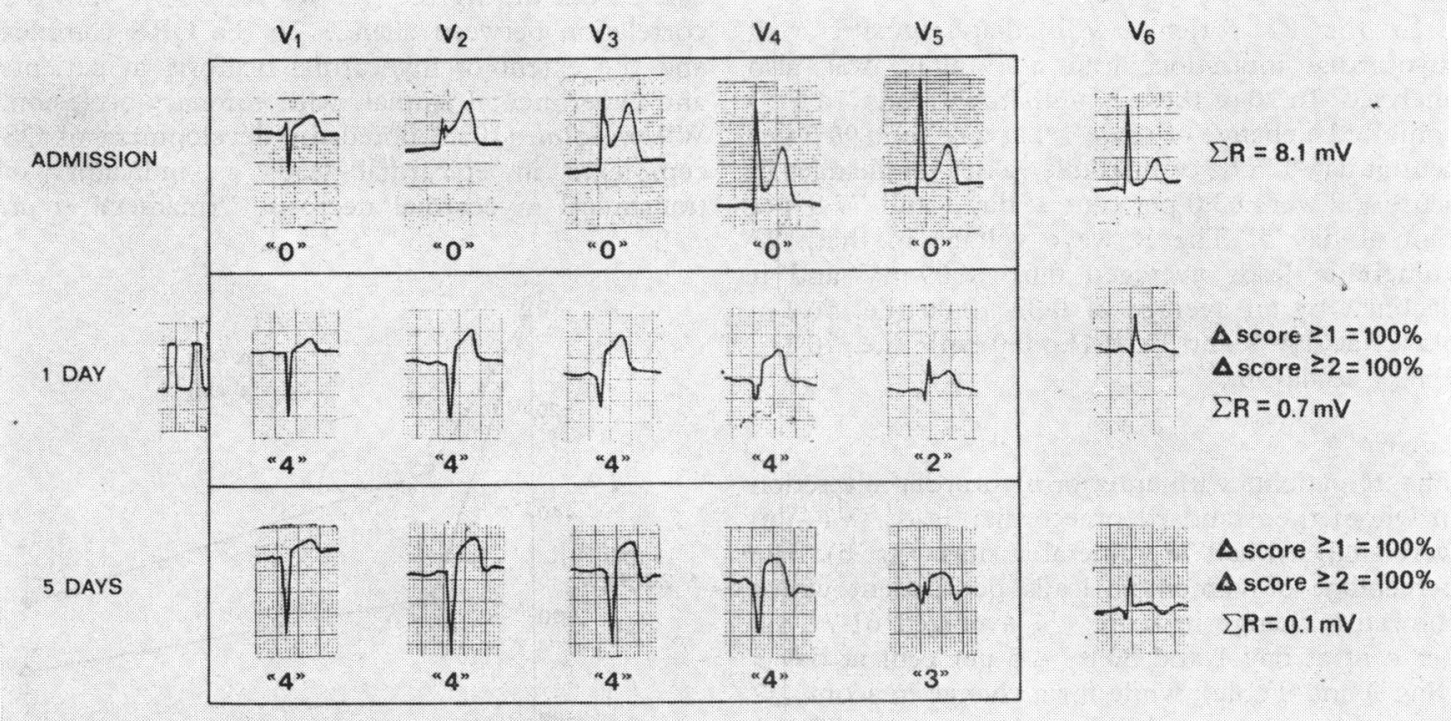

Fig. 6 Praecordial leads V1 to V6 from a patient with acute anterior myocardial infarction. Five of these leads (V1V5) are considered to be vulnerable to the development of electrocardiographic signs of necrosis. The scores are indicated below each tracing. Within one day all 5 sites $(100 \%)$ have changed score by 2 or more. $\Sigma R$ fell by 91 per cent of control $\frac{8.1 \mathrm{mV}-0.7 \mathrm{mV}}{8.1 \mathrm{mV}}$ in the first day and by 99 per cent in 5 days.

Table Alterations in $Q R S$ complex in 5 daysanterior myocardial infarction

\begin{tabular}{lccc}
\hline Case No. & $\% \downarrow \Sigma R_{\text {sd }}$ & $\% \Delta$ score $\geq 1_{\text {sd }}$ & $\% \Delta$ score $\geq 2_{\text {sd }}$ \\
\hline 1 & 35 & 67 & 0 \\
2 & 48 & 60 & 25 \\
3 & 67 & 50 & 0 \\
4 & 100 & 100 & 50 \\
5 & 100 & 100 & 100 \\
6 & 100 & 100 & 100 \\
7 & 100 & 100 & 100 \\
8 & 87 & 100 & 50 \\
9 & 93 & 100 & 75 \\
10 & 100 & 100 & 50 \\
11 & 100 & 100 & 100 \\
12 & 43 & 67 & 67 \\
13 & 96 & 75 & 66 \\
14 & 100 & 100 & 100 \\
15 & 80 & 50 & 50 \\
16 & 56 & 100 & 100 \\
17 & 98 & 67 & 67 \\
18 & 46 & 50 & 0 \\
19 & 76 & 100 & 20 \\
20 & 42 & 33 & 0 \\
21 & 46 & 67 & 33 \\
22 & 68 & 100 & 100 \\
23 & 97 & 86 & 75 \\
24 & 50 & 67 & 33 \\
Mean & $76 \cdot 1$ & $80 \cdot 8$ & $56 \cdot 7$ \\
SD & $24 \cdot 0$ & $20 \cdot 9$ & $36 \cdot 5$ \\
SE & $4 \cdot 9$ & $4 \cdot 4$ & $7 \cdot 5$ \\
\hline
\end{tabular}

(1954) and Shaw et al. (1954) analysed the origin of the QS complex in detail. They pointed out that the outer layers of the myocardium were ordinarily responsible for the $\mathrm{R}$ wave and stated that 'death of muscle in the outer ventricular layers eliminates or reduces the magnitude of the positive epicardial potential'. These investigators also observed that a QR pattern in epicardial leads might reflect the presence of a mixture of viable and necrotic myocardial cells.

Wilson et al. (1944) suggested that praecordial electrocardiograms provided information concerning the portion of the myocardium closest to the exploring electrode and termed these leads 'semidirect leads'. Extensive clinico-pathological correlations were then carried out by Myers et al., who established the relation between electrocardiographic abnormalities in particular leads and the occurrence of infarction in specific areas of the myocardium (Myers et al., 1948a, b; 1949a, b, c).

More recently, the relation between the appearance of new $Q$ waves, the fall in $R$ waves, and the development of myocardial necrosis were reexamined in our laboratory (Radvany et al., 1975; 
Hillis et al., 1976). Studies in dogs 24 hours after an experimentally produced coronary occlusion showed a highly significant correlation between the development of epicardial $Q$ waves, the diminution of $\mathbf{R}$ wave voltages, and depression of myocardial creatine kinase (CK) activity and the histological appearance of myocardial infarction at the corresponding epicardial sites. Moreover, it was shown that epicardial ST segment elevation shortly after coronary occlusion accurately predicts the extent of subsequent myocardial infarction, as reflected in the reduction of myocardial CK activity, in the histological appearance of the myocardium as well as in the changes in the QRS complex (Hillis et al., 1976). In other studies we observed that ST segment elevations, both in praecordial and epicardial leads, correlate well with the subsequent development of myocardial necrosis (Muller et al., 1975).

One of the major objectives of the present study was to provide a quantitative description of the evolution of the QRS complex in patients with acute myocardial infarction. However, the aim of this study was not to determine the rate of fall of $R$ wave or the appearance of pathological $Q$ waves. Rather, the principal finding is that within 5 days of admission approximately two-thirds of the leads which present with ST segment elevations $\geq 0.15 \mathrm{mV}$ within 8 hours after the onset of chest pain develop electrocardiographic signs of necrosis, as reflected in the development of new, pathological $Q$ waves $(\geq 0.2 \mathrm{mV}$ and $\geq 40 \mathrm{~ms}$ ). These leads also develop striking reductions in the $R$ wave, i.e. reductions of the order of 70 per cent. The incidence of these changes were similar in leads II, III, and aVF in patients with diaphragmatic wall infarcts, and in the praecordial leads V1 through V6 in patients with anterior myocardial infarction. In the former group, the analysis of aVF alone or II, III, and aVF provided similar results, suggesting that even when only one lead is analysed the progression of the necrotic process can be assessed.

To apply this approach clinically, we propose to use the praecordial ST segment recorded as early as possible after the onset of the clinical event as a predictor of the ultimate fate of the tissue in a manner analogous to the epicardial ST segment in the experimental animal. This praecordial ST segment may then be compared with the changes in the QRS complex that occur subsequently, such as the development or deepening of $Q$ waves and the reduction of $R$ waves; these changes in the $Q R S$ complex could be employed in a manner analogous to the alterations in CK activity or histological appearance of the myocardium subjacent to the epicardial electrode in the experimental animal. It should be emphasised, however, that this group of patients should not be used as a control group for future studies but rather during each investigation the patients should be randomised into control and treated groups and the evolutive QRS changes compared.

Before applying this method clinically, it was necessary to obtain a clear picture of the natural evolution of changes in the QRS complex in patients with acute myocardial infarction who had no treatment to protect ischaemic myocardium. The present study provides this picture; it indicates that the evolution of the QRS complex is quite predictable and that there is relatively little variability in the extent of electrocardiographic changes occurring in the vulnerable sites with transmural myocardial infarction when the initial tracing is obtained less than 8 hours after the onset of the clinical event. If, with the application of an intervention, the decline in $\Sigma R$ and the change in score occurring in vulnerable sites were significantly less than in a comparable group of control patients, it would be consistent with a beneficial effect.

The proposed simultaneous analysis of the ST segment and QRS wave alterations, while not capable of expressing the mass of infarcted myocardium in quantitative terms, appears to be: (1) capable of predicting the surface representation of the extent of necrosis to be expected when much of the myocardial injury is still in a reversible phase, i.e. at a time of ST segment elevation, before the development of changes in the QRS complex; (2) capable of assessing the surface representation of the extent of necrosis that actually develops, as reflected in the change in the QRS complex; (3) capable of being applied immediately, i.e. without requiring any delay in therapy; (4) safe and atraumatic; and (5) simple to apply, easy to interpret, and inexpensive.

\section{References}

Borer, J. S., Redwood, D. R., Levitt, B., Cagin, N., Bianchi, C., Vallin, H., and Epstein, S. E. (1975). Reduction in myocardial ischemia with nitroglycerin or nitroglycerin plus phenylephrine administered during acute myocardial infarction. New England fournal of Medicine, 293, 10081012.

Braunwald, E., and Maroko, P. R. (1974). The reduction of infarct size-an idea whose time (for testing) has come. Circulation, 50, 206-209.

Come, P. C., Flaherty, J. T., Baird, M. G., Rouleau, J. R. Weisfeldt, M. L., Greene, H. L., Becker, L., and Pitt, B. (1975). Reversal by phenylephrine of the beneficial effects of intravenous nitroglycerin in patients with acute myocardial infarction. New England fournal of Medicine 293, 1003-1007.

Dizadji, H., Nissen, R., Mathew, M., Hoesley, J. B., and Cernock, W. (1972). Myocardial infarction. Mortality factors in coronary care units. Geriatrics, 27(12), 76-86.

Epstein, S. E., Kent, K. M., Goldstein, R. E., Borer, J. S., 
and Redwood, D. R. (1975). Reduction of ischemic injury by nitroglycerin during acute myocardial infarction. New England fournal of Medicine, 292, 29-35.

Flaherty, J. T., Reid, P. R., Kelly, D. T., Taylor, D. R., Weisfeldt, M. L., and Pitt, B. (1975). Intravenous nitroglycerin in acute myocardial infarction. Circulation, 51, 132-139.

Harnarayan, C., Bennett, M. A., Pentecost, B. L., and Brewer, D. B. (1970). Quantitative study of infarcted myocardium in cardiogenic shock. British Heart fournal, 32, 728-732.

Hillis, L. D., Askenazi, J., Braunwald, E., Radvany, P., Muller, J. E., Fishbein, M. C., and Maroko, P. R. (1976). Use of changes in the epicardial QRS complex to assess interventions which modify the extent of myocardial necrosis following coronary artery occlusion. Circulation, 54, 591-598.

Hirshfeld, J. W., Jr., Borer, J. S., Goldstein, R. E., Barrett, M. J., and Epstein, S. E. (1974). Reduction in severity and extent of myocardial infarction when nitroglycerin and methoxamine are administered during coronary occlusion. Circulation, 49, 291-297.

Maroko, P. R., and Braunwald, E. (1973). Modification of myocardial infarction size after coronary occlusion. Annals of Internal Medicine, 79, 720-733.

Maroko, P. R., Davidson, D. M., Libby, P., Hagan, A. D., and Braunwald, E. (1975). Effects of hyaluronidase administration on myocardial ischemic injury in acute infarction. A preliminary study in 24 patients. Annals of Internal Medicine, 82, 516-520.

Maroko, P. R., Kjekshus, J. K., Sobel, B. E., Watanabe, T., Covell, J. W., Ross, J., Jr., and Braunwald, E. (1971). Factors influencing infarct size following experimental coronary artery occlusions. Circulation, 43, 67-82.

Maroko, P. R., Libby, P., Covell, J. W., Sobel, B. E., Ross, J., Jr., and Braunwald, E. (1972a). Precordial S-T segment elevation mapping: an atraumatic method for assessing alterations in the extent of myocardial ischemic injury. The effects of pharmacologic and hemodynamic interventions. American fournal of Cardiology, 29, 223-230.

Maroko, P. R., Libby, P., Sobel, B. E., Bloor, C. M., Sybers, H. D., Shell, W. E., Covell, J. W., and Braunwald, E. (1972b). Effect of glucose-insulin-potassium infusion on myocardial infarction following experimental coronary artery occlusion. Circulation, 45, 1160-1175.

Muller, J. E., Maroko, P. R., and Braunwald, E. (1975). Evaluation of precordial electrocardiographic mapping as a means of assessing changes in myocardial ischemic injury. Circulation, 52, 16-27.

Myers, G. B., Klein, H. A., and Hiratzka, T. (1948a). II. Correlation of the electrocardiographic and pathologic findings in large anterolateral infarcts. American Heart fournal, 36, 838-881.

Myers, G. B., Klein, H. A., and Hiratzka, T. (1949a). III. Correlation of electrocardiographic and pathologic findings in anteroposterior infarction. American Heart fournal, 37, 205-236.

Myers, G. B., Klein, H. A., and Hiratzka, T. (1949b). IV. Correlation of electrocardiographic and pathologic findings in infarction of the interventricular septum and right ventricle. American Heart fournal, 37, 720-770.

Myers, G. B., Klein, H. A., and Stofer, B. E. (1948b). I.
Correlation of electrocardiographic and pathologic findings in anteroseptal infarction. American Heart fournal, 36, 535-575.

Myers, G. B., Klein, H. A., and Stofer, B. E. (1949c). VII. Correlation of electrocardiographic and pathologic findings in lateral infarction. American Heart fournal, 37, 374-417.

Page, D. L., Caulfield, J. B., Kastor, J. A., DeSanctis, R. W. and Sanders, C. A. (1971). Myocardial changes associated with cardiogenic shock. New England Fournal of Medicine, 285, 133-137.

Prinzmetal, M., Kennamer, R., and Maxwell, M. (1954). Studies on the mechanism of ventricular activity. VIII. The genesis of the coronary QS wave in through-and-through infarction. American fournal of Medicine, 17, 610-613.

Radvany, P., Askenazi, J., Maroko, P. R., and Braunwald, E. (1975). Predictive value of ST segment in the development of electrocardiographic signs of necrosis after experimental coronary artery occlusion. Circulation, 52, Suppl. II, II-6.

Redwood, D. R., Smith, E. R. and Epstein, S. E. (1972). Coronary artery occlusion in the conscious dog. Effects of alterations in heart rate and arterial pressure on the degree of myocardial ischemia. Circulation, 46, 323-332.

Reid, P. R., Taylor, D. R., Kelly, D. T., Weisfeldt, M. L. Humphries, J. O., Ross, R. S., and Pitt, B. (1974). Myocardial-infarct extension detected by precordial STsegment mapping. New England fournal of Medicine, 290, 123-128.

Reimer, K. A., Kloner, R. A., Willerson, J. T., and Jennings, R. B. (1975). Reduction of infarct size by mannitol during acute myocardial ischemia. Circulation, 52, Suppl. II, II64.

Reimer, K. A., Rasmussen, M. M., and Jennings, R. B. (1973). Reduction by propranolol of myocardial necrosis following temporary coronary artery occlusion in dogs. Circulation Research, 33, 353-363.

Scheidt, S., Ascheim, R., and Killip, T., III. (1970). Shock after acute myocardial infarction. A clinical and hemodynamic profile. American fournal of Cardiology, 26, 556564.

Shaw, C. McK., Goldman, A., Kennamer, R., Kimura, N., Lindgren, I., Maxwell, M. H., and Prinzmetal, M. (1954). Studies on the mechanism of ventricular activity. VII. The origin of the coronary QR wave. American fournal of Medicine, 16, 490-503.

Snedecor, G. W., and Cochran, W. G. (1967). Statistical Methods, 6th ed. The Iowa State University Press, Ames.

Wilson, F. N., Johnston, F. D., Rosenbaum F., Erlanger, H., Kossmann, C. E., Hecht, H., Cotrim, N., Menezes de Oliveira, R., Scarsi, R., and Barker, P. S. (1944). The precordial electrocardiogram. American Heart fournal, 27, 19-85.

Wilson, F. N., MacLeod, A. G., Barker, P. S., Johnston, F. D., and Klostermeyer, L. L. (1933). The electrocardiogram in myocardial infarction with particular reference to the initial deflections of the ventricular complex. Heart, 16, 155-176.

Requests for reprints to Dr. Peter R. Maroko, Harvard Medical School, Bldg. A, 25 Shattuck Street, Boston, Massachusetts 02115, U.S.A. 